\title{
Mapping migrant territories as topological deformations of space
}

Our research uses the concept of 'territories' to describe the production of migrant space. The article describes a project based in London where the everyday practice of walking is used to map migrant territories, which are conceptualised as dispersed and overlapping, causing topological deformations to the actual lived space. We interrogate these deformations through focusing on the micro-scale and the everyday, mapping them as 'scapes' and 'spheres'. Using specific computational techniques we transform the original walks into an architectural tool for investigating the fluctuations and flows of the contemporary city. In doing so, we approach territories from two distinct angles: from the geopolitical perspective of territories seen as the product of the interplay of politics, power and space, and from the biological perspective of territories seen as the primal need of all animals, including humans, for space and a certain distinction from their environment and from others.

Keywords: territories, topological deformations, spheres, mapping, walking, artificial neural networks

$\begin{array}{ll}\text { Nishat Awan (Corresponding author) } & \text { Phil Langley } \\ \text { School of Architecture } & \text { University of Sheffield } \\ \text { University of Sheffield } & 120 \text { Brooke Road } \\ \text { Arts Tower, Western Bank } & \text { London N16 7RS } \\ \text { Sheffield S10 2TN, UK } & \text { e: phil@openkhana.net } \\ \text { e: } \underline{\text { n.awan@sheffield.ac.uk }} & \text { Phil Langley } \\ & \text { University of Sheffield } \\ & 120 \text { Brooke Road } \\ & \text { London N16 7RS } \\ \text { e: phil@openkhana.net }\end{array}$

Nishat Awan is a Lecturer at University of Sheffield. Her research interests include the politics and representation of migratory spaces, geo-politics and alternative architectural practice. She is co-author of, Spatial Agency (forthcoming Routledge, 2011) and co-editor of Trans-Local-Act (aaa-peprav, 2011). She has worked in architectural practice for a number of years and holds a PhD in Architecture from the University of Sheffield, UK.

Phil Langley is an architect and computational designer based in London and a PhD candidate at University of Sheffield. His research focuses on the interface between digital design techniques and architectural practice. He has collaborated with architects and designers, developing interactive software for installations and websites.

Nishat Awan and Phil Langley are members of OPENkhana, a collaborative that works between architectural, artistic and computational practice. The software described in this article will be published on the website openkhana.net. 


\section{Acknowledgements:}

This article forms part of research carried out at the University of Sheffield and University of East London funded by the Arts and Humanities Research Council, UK. 


\section{Mapping migrant territories as topological deformations of space}

Our research uses the concept of 'territories' to describe the production of migrant space. In so doing, we approach territories from two distinct angles: from the geopolitical perspective of territories seen as the product of the interplay of politics, power and space, and from the biological perspective of territories seen as the primal need of all animals including humans, for space and a certain distinction from their environment, and from others. We conceptualise these migrant territories as dispersed and overlapping, causing topological deformations to the actual lived space, and we interrogate these deformations through focusing on the micro-scale and the everyday, mapping them as 'scapes' (Appadurai, 1996), 'spheres' (Sloterdijk, 1998; 1999; 2004) and 'umwelt. (von Uexküll, 1926). We use the concept of 'spatial deformations' to refer to the way space, subjectivity and politics influence each other and are coproduced, foregrounding issues of belonging and inclusion. Each person's inhabitation of space has certain effects, opening up moments of agency and affect in city-space. The mapping of these territories is linked to an understanding of such processes as being produced through our bodily practices (Grosz, 1995). We therefore start mapping at the level of bodily detail using various techniques, including photographing, conversations, walking, and then finally using computational methods to map the topological relations of and between the territories that emerge in these practices. In doing this, we try to keep the poetic and political dimensions of the original walks and conversations: we try not to lose their subjective qualities.

In our desire to think territories as both political and biological we chose to use the everyday practice of walkingtogether as a method because reality is never the same for two people and the street on which we walk is very different from the one others may walk and experience. Both the act of walking itself, and its later mapping and analysis, were a way of trying to discover how the reality of a space that we were highly familiar with differed from person to person. The walks occurred on a single street in north-east London where a large number of Turks and Kurds live. Here the use of walking also seemed appropriate as the street is the site of regular protests by Kurdish groups in the area; it is thus already a highly charged activity, being used regularly to mark out and traverse territories. In our walks with Kurds and Turks we became acutely aware of how different their experiences of the street were; where one saw a building that housed a community organisation, another saw a hotbed of 'terrorist activity'. 'We realised that the way political territories affect the personal territories of those in the diaspora is through this always already fragmented point of view, and any attempt at mapping migrant territories needed to account for this deformation of space through regional, political and other affiliations. [Fig. 1]

The project is based along a single stretch of street in the London Borough of Hackney, which is situated in the northeast of inner London. The southern tip of the borough sits adjacent to the City with private development encroaching northwards. The site of the project, Stoke Newington High Street / Kingsland Road, runs north-south and extends from Stoke Newington to Dalston, areas where recent gated developments sit next to large social housing estates. The project ran from summer 2007 to the end of 2008, a particularly intense moment in the transition of the area where significant 'regeneration' is underway, including the demolition of prominent existing buildings and the construction of new residential towers, as well as new transport infrastructure related to the London Olympics in 2012. Such private/public regeneration is accompanied with the production of many maps—development plans 
indicating opportunities, constraints, zones and phases. These mappings represent a bureaucratic exercise intended to create a formal record of a developmental process rather than encouraging a situation in which dialogue and participation are possible. They do not describe an urban condition at that particular moment, nor an idealised situation in the future that could be realised, instead they are merely a pre-determined stage in the process of 'regeneration'. These maps are linked to the requirement for participation and user consultation in the planning process. Although opinions are sought and questions asked, in the end the limited nature of the choices and what is highlighted and enframed in these discussions, leaves no room for any real discussion or conflict - the outcome is predetermined and the maps record a process in order to meet the obligation to 'participate'. It is within this context that our mappings propose an alternative tool that is more situated in the local condition, rather than generically applied to it. Mapping can also be a continual, cyclical practice that does not occur simply to legitimise development but instead is a critical practice that questions easily held assumptions regarding the use and value of city-space (Altay, 2009; 3Cs: Counter Cartographies Collective, 2009; Sen, 2007). Hard-won communal spaces, whether they take the form of the semi-private kahve (Turkish and Kurdish social clubs) or the community centres set-up in disused buildings, are being pushed out as the area becomes desirable again. For example, Halkevi, an important Kurdish and Turkish community centre, occupying part of a building on the street, has been forced out of its premises through large-scale rent increases and the building itself converted to 'loft-style' apartments. Ironically, the parts of the building that Halkevi occupied remain empty. The type of walking and mapping practice that we are describing is therefore a political act that seeks to valorise the neglected and overlooked narratives of the city and is conceived in opposition to the developmental maps described above. Our mappings aim to become tools that could be used within an alternative and participatory planning process.

\section{New tools for mapping migrant space}

The migrant is by condition political, both due to past events and present realities and any mapping of diasporic territory therefore needs to engage with the ways in which the geopolitical realities of other places are inscribed on to the bodily practices of the migrant. Using walking-with as a technique allowed us to privilege the personal and the political, and we conceptualised it as a way of mapping 'micro-territories' that form, dissolve and overlap around us all, influenced by our specific circumstances and spatial politics. They can be considered as a kind of field or sphere of influence, overlapping, constricting and merging as we encounter different people and places. We mapped these fluctuating 'diasporic territories' by carrying out walks with people who have differing, sometimes highly opposing political views. The juxtaposition and overlaying of these walks produced a representation of migrant territory that was also a way of taking what were highly individual points of view (the mapping of personal territories) and representing them collectively through mapping affiliative or political territories. Whilst walking together we carried out informal interviews along the individualised trajectories of those we walked with (Anderson, 2004; Precarias a la deriva, 2004). We spoke together about the neighbourhood, and in particular about the street, exchanging experiences about the different places we frequented and the people we knew. The walks were therefore performative, acted out within the public space of the street, and any representation of them needed to convey their spatial, durational and experiential logic." Our mapping techniques also gave importance to small-scale details and events, mixing this close looking with 
specific architectural strategies, including computational methods. The question of technology interests us — how is it possible to use new technologies without fetishising the technique and without losing the poetic and personalised quality of a method of working that privileges the subjective and the narrational. The use of computational methods was also an attempt to transform walking, which is viewed within a certain tradition as an artistic practice, into a specific architectural tool that could be reused in another setting.iii Such techniques allow for a level of generality and repetition to be inserted into what is a highly subjective process. Here the mappings can also be thought of as new ways of imagining the city and its spaces through foregrounding the conflictual nature of city-space. [Fig. 2]

Proposed as both a methodology and a resource, our maps are intended to contribute to an open, web-based archive where simple bits of information can be added and readily translated into territorial maps. Currently the software, which is scripted in the open source platform Processing, ${ }^{\text {iv }}$ is at the level of an interface for exploring the territories as visualisations and as a means of reconnecting these abstracted representations back into the context of the street. The photographic elevations at the top and bottom of the screen act as a navigational device allowing the user to explore the territorial maps in 'section'. ' [Fig. 3] We were interested in creating a mapping tool where the architect (in this case ourselves) was no longer essential to the process of mapping. An example of such an approach is the OneTrees project by Natalie Jeremijenko (Jeremijenko, n.d.), where rather than creating a single or a series of maps, a mapping system is established. Cloned trees were propagated in the laboratory and later planted at various sites across the Bay Area, USA. These artificially grown, genetically identical trees became living tools for mapping and their progress over the years not only indicates the environmental quality of their habitat but also allowed the trees to become social indicators, as the trees were assigned stewards to look after their welfare. Combined with a paper leaflet that gave the locations of the trees, information on wildlife in the area and other data, the trees became part of a large scale mapping system that involved the local community in their environment. As Jeremijenko comments the map itself becomes, 'an instrument that collects information as much as it disseminates it' (Twemlow, 2006). Through this acceding of responsibility for mapping to others, Jeremijenko was able to allow for a long-term and participatory mapping process to occur and this is also an aim in the development of our mapping website.

\section{Neural Territories}

A practice of collective mapping of migrant space that emphasises the relations between different people's territories, and the way in which they affect each other, required a shift in thinking: from the Euclidean space of normative architectural practice to a different kind of space, one that is heterogenous, multiple and communicative. ${ }^{\text {vi }}$ Starting in Euclidean space, a representation of the street as a standard map, our walking practice provided spatial 'inputs': what shop do you use, which cafe do you go to? In addition, this simple information was enriched with time-when do you use that shop, when do you go for coffee? This small step - adding information about time to that about space already moved us beyond the Euclidean. However, the question here is not simply about how to map 4D information, instead the dimension of time implies the overlapping and intersecting of spatial occupancy and appropriation. In order to map the fluctuations of someone's territory, we needed to move away from ideas around 3D or even 4D systems, and into a relational or topological space. This can be understood as the removal of Euclidean metrics instances are no longer defined through orders of magnitude $(1,2,3 \ldots)$ - and their replacement by 'relations' - 
convergence, continuity, connectedness. The map no longer simply indicates which shop someone went to and when, instead it starts to show a field of influence, how certain events or the presence and absence of certain people and places changes the mapped territory. In this sense, the mappings move into a topological space of possibilities and the mapping tool becomes propositional.

For example, whilst walking with a young Turkish man who worked as a waiter in a local café, we walked past the community centre Halkevi; he commented that he did not like walking on the same side of the street as the building in which the centre was housed, and claimed that the Turkish secret police were operating there. In another walk with a Kurdish woman, the mosque was a place to go into only on certain specified days. It was clear that both these places and various others have their own field of influence, which affect certain people but not others, and that they not only act independently but also influence each other.

In order to create a map that is also able to respond in such ways to people, places and events, we used the technique of Artificial Neural Networks [ANN]. ${ }^{\text {vii }}$ ANNs are mathematical models inspired by the structure and functional aspects of biological neural networks, where the transmission of information through synapses and neurons in the brain is represented by nodes and connections within a computational system that is able to process inputs and create outputs. [Fig. 4] Usually such programmes are used to model complex relationships and patterns in datasets, typically being used for classification, for example in face recognition software. There are a range of different types of neural networks that vary in topological organisation, and consequently in the transmission of data. For this project, we developed a specific ANN derived from 'The Self Organising map' [SOM] (Kohonen, 2001), which is typically a 2 dimensional map of $n$ dimensional inputs. In cognitive and computational science, the SOM is used as a tool for categorisation, a simple example is its use in determining a colour range as RGB values. [Fig. 5] The basic algorithmic principle consists of two stages, training and calibration. The first stage involves the training of the network with a limited range of inputs (in this case sample RGB values). The second, calibration, is carried out through the classification of further, discrete input data into the trained map, for example by using further RGB input values and identifying the colour 'zone' into which these are mapped.

Let us make a first cautionary point. There is a certain fallacy of 'exactness' when using computational methods that the ANN addresses - a conflation between precision and accuracy. Whilst standard computational processes are very precise, they are not necessarily accurate since this quality depends on the original input. The ANN is also computationally very precise but the output it produces is quite imprecise or 'fuzzy'-it is, in fact, attempting to map complex but incomplete inputs. In the example above, the SOM was 'presented' with a set of input data, consisting of eight colours described as RGB values. These were 'interpreted' and then 're-presented' as a generalised output, which filled 'the gaps' between the original inputs. The network has created the range of colours in between the discrete set of initial data. Thus, the nature of ANNs is to take precise but 'incomplete' data, and to create an imprecise but 'complete' output map. It is this 'behaviour' of ANNs that is crucial to our mapping, and which we sought to develop.

Whilst the network used for the RGB inputs was very simple, other aspects of the walks required a more sophisticated approach. The example above of the SOM has a fixed topology (structure of connection)] and a fixed size (number of nodes), but there are other types of 'growing' ANNs that are able to change their size. For mapping 
other aspects of the walks, we used a type of ANN that can adapt both its size (i.e. it can grow and shrink) and topology according to the initial inputs (Langley, 2007). ${ }^{\text {vii }}$ [Fig 6] Rather than adopting the typical classification mode of SOMs, we took a different approach, based in the observation that just as in real life the relations between people, objects and spaces are altered as soon as something extra is added or someone else arrives, so the same is also true for a neural network, which is in essence a map of relations. It is solely a representation of the original inputs there is no field upon which inputs are distributed and therefore there can be no categories, only relations. The advantage for us in using ANNs lies not in their ability to provide classifications of data, but to provide approximations of it. In fact, what is mapped are topological relationships rather than topographic descriptions. [Fig 7]

Our ANN was thus developed to create a 'relational map' of each person's walk, the input data being a quasispatial/temporal point cloud that was generated from the initial walks and conversations. BY comparing different walks in a relational map, it became possible to analyse the significance of difference or similarity, rather than merely its existence because the sensitivity of the network to even very small changes in the input data meant that we were able to address the proximate scales of everyday life. Using the walks as input also gave a level of lived accuracy to the original information, which can be contrasted to the technical accuracy of some other mapping systems. Unlike the recent use of technologies such as Global Positioning System [GPS] tracking, this way of gathering information is grounded in actual experience. Most GPS systems map to a $2-1.5 \mathrm{~m}$ accuracy and in the space of a street, for example in London where Victorian pavements are generally $2 \mathrm{~m}$ wide, it is the difference between being inside or outside. The politics and poetics of those two meters is what we tried to map through our walking. To walk with someone means to spend time with them - it is also an ethical choice; the use of GPS, a military technology, keeps a distance and brings back the detached perspective of the traditional cartographer (Petrescu, 2007; Holmes, 2004). But, in a similar way to the video-essays of film-maker, Ursula Biemann, we do not reject the technological but try to use it in a critical manner. Biemann's (2002, Biemann \& Lundström 2007) use of different technologies and the layering and overcoding of narrative, data and interviews creates a representational style that allows a topic or an issue to be addressed from multiple perspectives. We also adopted this approach of layering information and sought to represent the walks in a way that did not flatten, but opens up points of access and possibility, especially as different mappings are overlaid and varied trajectories can be traced from one person's territory to another. The tracing, understanding and multiplication of these agencies described as spatial deformations is central to the architectural purpose of the mappings we produce. They go beyond simple descriptions of physical space to describe the complex processes that produce migrant spatiality, including layers of the political, religious, cultural, gendered and the economic. [Fig. 8]

\section{'Spheres', 'scapes','umwelt ...}

This way of mapping that relies on the space, or 'sphere', of each individual is based on a very specific conceptualisation of territory-at the level of the individual and with each individual considered both in the sense of politics as well as corporeality. This is a social space in the sense that Lefebvre (1991) would describe it, but for us where Lefebvre's analysis falls short, is finally, how to work with this space-how to intervene in it as architects. And, of course, since The Production of Space (Lefebvre, 1991) was written, the world has changed considerably through 
increased communication and migration; the effects of globalisation. These effects are described most saliently perhaps in the work of Appadurai (1996) whose conceptualisation of the different types of 'scapes', such as those related to the media or to politically and economically striated global spaces, provides a useful framework for thinking migrant spatiality. Appadurai also uses the term 'diasporic public sphere' to describe the sorts of spaces that are proliferating in most major cities around the world, springing up around their diasporic populations and fulfilling particular cultural and social needs. He gives examples of Turkish guest workers watching Turkish films in Germany, or Pakistani cab drivers in Chicago listening to sermons recorded in mosques in Pakistan and Iran. Through these examples Appadurai is writing of the particular types of spaces that are associated with migrant populations. It is interesting that both these examples occur in enclosed spaces, whether it is the domestic space of the home or its extension within the private car. How can these types of spaces be re-conceptualised and represented in the space of a street beyond enclosed walls, where there is the opportunity for an active overlapping of appropriated space? What possibilities for interaction between diverse groups can this provide? We suggest that another definition of the word 'sphere' is required, one that moves away from Habermasian notions of the 'public sphere' (Habermas, 1989), to another conceptualisation which could be useful for both thinking and representing diasporic territories.

\section{(a) Bio-territories}

Peter Sloterdijk's 'spherology' (Sloterdijk, 1998; 1999; 2004) provides one such route, using Lacanian psychoanalysis as a starting point to trace a Heideggerian 'Being in the world' that concentrates on the exact nature of the 'in' within that phrase; a concern that is traced at different scales in his trilogy, from the pre-natal to the global. It is the final volume of the trilogy, Foam, that provides a framework for thinking territory in the way that we have tried to map it. A kind of treatise for a post-human non-modern world, Foam is an account of a world of spatial multiplicities. In Sloterdijk's post-human stance it is impossible to describe a human without describing what it takes to live as a human, what environment, atmosphere or sphere is required-what support systems. 'Being in the world' here becomes an engagement with materiality and matter as the condition of our being human. Sloterdijk uses the metaphor of space stations to describe our relation to the world in which we live. Since the destruction of 'Mother Earth' both physically and symbolically, the figure of the 'space station' provides a way of thinking ecology in the sorts of relations that Donna Haraway's cyborg anticipated (Haraway, 1991). In the artificially generated atmosphere of the space station nothing is taken for granted, extreme care is required due to the fragility of the system. Sloterdijk speaks of the space station as, 'a model for being in a world condemned to artificiality.' (Sloterdijk, 2005, p. 236) (x $^{\text {ix }}$

Our concept of a territory based on the subjective worlds of non-humans who also have their own 'spheres' is also influenced by the work of the theoretical biologist, Jakob von Uexküll (1926). He proposed his biological theory of sphere, Umwelt, in the 1920s as a description of the world of living organisms, whose experience of the world was seen not only as being very different from that of humans (as subjective beings) but as constituting a different 'world'. His way of conceptualising different worlds or realities in fact foresaw many of the advances in quantum physics as well as in contemporary cultural and social theory. Uexküll used the term Umwelt to describe a world beyond the merely empirical scientific description of it as Welt. His most famous example comes from his description of the Umwelt of the tick-this simplest of insects whose world in comparison to that of the human seems so 'poor'. Described as blind and deaf, the female tick's life is dominated by the reproductive urge and she has only three 
sense signals: a particular smell, a sensitivity to a precise temperature and a sense of touch. She requires warm blood for her eggs to mature and so needs to find a warm-blooded mammal to act as a host. Since she cannot see her sense of smell guides her: as a mammal approaches giving off the scent of butyric acid, which our sweat contains, the tick senses her chance and drops from her elevated position. If she has, indeed, managed to land on a mammal, she will know this through her sensitivity to the exact 37 degrees temperature of mammalian blood, and her sense of touch will guide her to a suitable place in which to burrow into the skin. Uexküll prefaces this account of the tick's world with a description of the same place as humans would perceive it, an idyllic meadow full of colour and smell and sound. In comparison the tick's world seems so meagre. But as Giorgio Agamben has pointed out, in ways that we humans couldn't come close to understanding, the tick's world is full of richness: 'Yet the tick is immediately united to these three elements in an intense and passionate relationship the likes of it we might never find in the relationships that bind man to his apparently much richer world. The tick is this relationship; she lives only in it and for it.' (Agamben, 2004, p. 47)

What would a map of this world of the tick look like? Would it have three colours only, one for each of its three senses? Is it even possible to map the subjective world of an animal? A pair of architects from New York, Terraswarm, have attempted such a mapping of the visual world of a pigeon (Twemlow, 2006). The harnessing of pigeon flight for the use of humans has a long history, but Terraswarm are attempting something different. They try to apprehend the city from the pigeon's point of view as part of a flock in flight, technologically a highly ambitious undertaking, which is not yet perfected. A tiny camera is strapped to the pigeon's chest and they are set free. The mapping of their movements - created from what is recorded by the cameras that the pigeons wear - is carried out in the context of the 'Brooklyn Pigeon Wars', where the birds are trained to fly high above the rooftops, their encounter in the sky merging the flocks in an intricate performance that results in 'disoriented' birds joining the opposing flock. It seems the pigeon owners have an understanding of flock behaviour, planning strategies to win birds from different flocks. Terraswarm also seeks to understand flock behaviour through computer models developed by the games designer Craig Reynolds (Reynolds, 1987; 2001), but it seems these models do not draw on the observational knowledge of the pigeon coop owners gained through years of experience. The desire to use science and technology fails to valorise other ways of knowing, and in some ways Terraswarm do not manage to explore the pigeons' relationship to their context. This context does of course consist of all the environmental mappings that Terraswarm made: wind direction, local flight paths, the Earth's magnetic field, but it also includes the humans that must have formed some sort of relationship with the birds, and what of the relations the birds may make in the sky? Does flock behaviour only ever consist of the kinetics of 'separation, alignment and cohesion', ${ }^{x}$ what of the reasons for these movements? Homing pigeons are also highly territorial birds, ready to defend their 'patch', but this urge to territorialise is not constant, it waxes and wanes according to the pigeon's life cycle, affected by age, season etc. All these factors form part of the subjective world, the Umwelt of the pigeons.

These were the types of questions related to 'bio-territories' that we wanted to address in our own mapping practice HOW?, but of course whilst mapping the territories of humans. For this the political needed to also be foregrounded, especially because of the contested nature of the street we had chosen to map. 


\section{(b) Political Territories}

We therefore found it necessary to take a detour through contemporary territorial research in order to interrogate the relationship between power, politics and space, and how the representation of space motivated by politics is used as a means of exerting power. On a global and political scale, territory cannot be uncoupled from its representation and this point has been made especially successfully and dramatically in the context of Palestine/lsrael, in the work of Eyal Weizman and Rafi Segal. The need for territorial research within the discipline of architecture seems to be fundamentally connected with the need to address conflict as a base condition. Much of the work is predicated on the fragmentation of the notion of 'territory'-with the slow demise of the nation-state, globalised power structures and the state of constant war in which we now live, territory as a self-contained, discrete entity has fragmented into what has been referred to as an 'archipelago' or in the plural as 'territories' (Weizman, 2005). The analogy of the archipelago is useful as it keeps the notion of a level of containment and isolation, but adds to it connections and relations that are the result of exterior power applied from above, without the knowledge or consent of the majority. The concept of 'archipelago' thus refers to a dual condition, the fragmentation of sovereign power and the rise of extra-territorial powers. The fragmented islands of territory of an archipelago have fluid and temporal boundaries unlike the traditional notion of territory which is conceived as a bounded entity with clearly defined borders.

The importance of territories as a concept also reveals itself in other situations in which conflict is present but where it does not necessarily manifest itself in the violence of war. Ursula Biemann's video essays, in particular, focus on the biopolitics of territories and networks, and on how their production is performed socially through the politics of labour, gender and mobility. In her work the question of territory is explicitly linked to the corporeal. Biemann's video essay, Sahara Chronicle, is part of her wider curatorial project, The Maghreb Connection (Biemann \& Holmes, 2006). In the video she follows the journey that thousands of Africans take through Sub-Saharan Africa to the Maghreb in the hope of a passage to Europe. She has commented that her work is an attempt to show the other side of this journey than the usual story seen in Europe of failed passage and capsized boats. In contrast, the beginning of the journey is full of hope and a sense of excitement. Her video traces the network of people and places that allow this passage to occur, a recasting of Castells' concept of the 'network society' that describes the world of global finance (Castells, 1996), to the tribal structures of the nomadic Tuareg of the Sahara. It is also a reaction against the isolated eventbased take of the popular media to an understanding of migration as a condition.

The video also reveals the different ways of conceptualising territory, from the boundedness it is afforded in the West, to the right to pan-African mobility that the continent's inhabitants enjoyed until recently. Biemann makes the point that the Schengen agreement that made possible a Europe without borders also curtailed free movement in Africa by outsourcing European border security to the Maghreb (Biemann, November 2007). The construction of territory in Africa is therefore intimately connected to European power, but this power is also subverted and deterritorialised to a certain extent by the mobility of the Tuareg. They have historically been the natural passage providers between the southern and northern parts of Africa and the artificial split of their territory across four different countries by the colonial powers has left them in a state of limbo. They are by condition transnational and this makes their position ideal for facilitating the transit of others across the Sahara. In the clandestine movement of lines criss-crossing the vast desert, political territories are made and remade and the unsympathetic borders drawn by the receding European powers are rendered at least momentarily ineffectual. Biemann relates the deals that are struck for this 
passage, whether it is the money handed over to the Tuareg by the would-be migrants, or the diesel bought by local authorities in exchange for returning the unsuccessful migrants back across the desert. There is a parallel economic network shadowing the movement of bodies across distances and together these different trajectories constitute what could be characterised as a shifting migrant territory.

How can these two very different ways of conceptualising political territories - archipelago and trajectory - become useful in our mapping of a rather nondescript London street? Whilst it is easy to see the formidable workings of political power in places like Palestine, it is harder to imagine its work in a placid street where everyone seems able to go quietly about their business. It is therefore a matter of trying to unravel the intricate network of people and places that lead to power and the formation of political territories and the effect that the state and extraterritorial powers can have on the lives of those caught up in their wake. This was demonstrated time and again by the differing accounts of the same place recounted by the different people we walked with. The place from which the Kurds especially spoke was never a bounded, secure place, never a nation-state, and we were aware that our attempts to conceptualise migrant territory should also account for this other perspective.

Our project to map migrant territories was primarily an attempt to expand the representational practices of architecture and urbanism. Consequently, we also aim to expand the practice of mapping outwards to not only include the planning of spaces, but also the social and political aspects of the production of space. The project started with an understanding of migrant spatiality as inherently territorial, bringing with it the conflicts, nostalgias and attachments of another place. Sloterdijk's concept of 'spheres' allowed us to conceptualise these issues as being immediately spatial, imagined as 'personal territories' or 'spatial envelopes'. Conceptualising 'bio-territories' allowed us to include the non-anthropocentric, non-human perspectives of pigeons and ticks. These were included as part of an attempt to move away from the standards and conventions of representation, which in our own mappings was done through foregrounding subjective experience and through the use of computational techniques, making representations that privileged topological relations over topographic connections. The political perspectives just discussed were, therefore, included in order to facilitate more radical conceptions of space, representation and territorialisation. Political territories of migration and conflict add a further perspective that shows how the formation of territories is always related to questions of power and appropriation, and foregrounds the very different ways of conceptualising territories across cultures. In addressing the question of territory at the level of locality, our project concedes that the description of place is always related to the formation of territories, and in a highly diverse place like London, the many different ways of conceptualising territories beyond their bounded description needs to be addressed - the archipelagoes and trajectories of elsewhere also find their echoes in the reterritorialisation of space by migrants in London.

\section{Mapping migrant territories as topological deformations of space}

In this attempt at mapping migrant space we have privileged the method of walking-with, using it as a tool for a corporeal mapping of 'personal territories' that cause topological deformations to the actual lived space of the street, of affecting and being affected by our surroundings, our politics, our subjectivity. These spatial deformations were mapped using computational methods that allowed us to move beyond the conventions of traditional architectural 
representation, which restricts the spatial to the Euclidean space of $x-, y$ - and z-axes. The use of ANNs allowed us to switch to a type of representation that rather than mapping instances, mapped relations, overlaps and intensities, by allowing the territories of different people at different times to communicate and to connect topologically according to their particular spatial politics.

In addition, the developmental context in which we were operating, and in opposition to which we have tried to create an alternative planning tool, demanded a form of representation that could somehow mediate between the representational space of local government development plans and the lived, actual space of the walks. They needed to bring these other experiences to the planning table as equally legitimate and having their own authority. We are now working on a web-based application that will allow others to use the technique we have developed to map their own neighbourhoods. It will allow people to upload spatial, time-based information and conversations onto the website, which will synthesise the data into territorial maps. Our aim, of eventual relinquishing of control over the mapping through the web-based application in development, allows a shifting of spatial agency ${ }^{x i}$ from the professionalised space of architects and developers to that of the everyday user. 


\section{References}

3Cs: Counter Cartographies Collective. (2009). Retrieved from http://www.countercartographies.org/.

Agamben, G. (2004). The open: Man and animal (K. Attell, Trans.). Stanford: Stanford University.

Altay, C. (2009). In search of spatial practice. Seminar session presented at Lines of Flight research group, University of Sheffield, School of Architecture, Sheffield, UK. Retrieved from http://linesofflight.wordpress.com/2009/12/14/seminar-12-in-search-of-spatial-practice/.

Anderson, J. (2004). Talking whilst walking: A geographical archaeology of knowledge. Area, 36(3), 254-261. doi: 10.1111/j.0004-0894.2004.00222.x

Appadurai, A. (1996). Modernity at large: Cultural dimensions of globalisation. Minneapolis: University of Minnesota Press.

Awan, N., Schneider, T. \& Till, J. (2011). Spatial agency: Other ways of doing architecture. London: Routledge.

Biemann, U. (2002). Remotely sensed: A topography of the global sex trade. Feminist Review, 70, 75-88. doi:10.1057/palgrave.fr.9400216

----, (2007, November). The Maghreb connection. Paper session presented at ${ }^{\text {rd }}$ International Symposium Art Critics in a Global World, Museu d'Art Contemporani de Barcelona (MACBA) Spain.

Biemann, U., \& Holmes, B. (Eds.). (2006). The Maghreb connection: Movements of life across North Africa. Barcelona: Actar.

Biemann, U., \& Lundström, J. E. (Eds.). (2008). Mission reports, artistic practice in the field: Ursula Biemann video works 1998-2008. Bristol: Arnolfini.

Careri, F. (2003). Walkscapes: Walking as an aesthetic practice (S. Piccolo \& P. Hammond, Trans.). Barcelona: Editorial Gustavo Gili.

Castells, M. (1996). The rise of the network society: Vol 1. Cambridge, MA: Blackwell.

Derix, C. (2004). Building a synthetic cognizer. Paper session presented at MIT Design Computational Cognition Conference, Cambridge, MA.

Grosz, E. (1995). Space, time and perversion: Essays on the politics of bodies. London: Routledge.

Habermas, J. (1989). The structural transformation of the public sphere: An inquiry into a category of bourgeois society (T. Burger w. F. Lawrence, Trans.). Cambridge: Polity.

Haraway, D. J. (1991). Simians, cyborgs and women: The reinvention of nature. London: Free Association.

Holmes, B. (2004). Drifting through the grid: Psychogeography and imperial infrastructure. Springerin, 3. Retrieved from http://www.springerin.at/en/

Jeremijenko, N. (n.d.). OneTrees: An information environment. Retrieved from http://www.nyu.edu/projects/xdesign/onetrees/.

Kohonen, T. (2001). Self-organizing maps ( $3^{\text {rd }}$ ed.). Berlin: Springer.

Langley, P. (2007). Meta cognitive mappings: Growing neural networks for a generative urbanism (Unpublished master's thesis). University of East London, UK. 
Lefebvre, H. (1991). The production of space (D. Nicholson-Smith, Trans.). Oxford: Basil Blackwell.

Petrescu, D. (Ed.). (2006). Altering practices: Feminist politics and poetics of space. London: Routledge.

Petrescu, D. (2007). The indeterminate mapping of the common. Field: 1(1), 88-96; http://www.fieldjournal.org/index.php?page=2007-volume-1

Precarias a la deriva. (2004). A drift through the circuits of feminized precarious work. Feminist Review, 77(1), 157161. doi:10.1057/palgrave.fr.9400162

Processing. (n.d.). Retrieved from http://processing.org/

Rendell, J. (Ed.). (2000). Gender, Space and Architecture. London: Routledge.

Reynolds, C. W. (1987). Flocks, herds, and schools: A distributed behavioral model. Computer Graphics, 21(4) (SIGGRAPH '87 Conference Proceedings), 25-34.

----, (2001). Boids: Background and update. Retrieved from http://www.red3d.com/cwr/boids/.

Sen, J. (2007). Other worlds, other maps: Mapping the unintended city. In L. Mogel \& A. Bhagat (Eds.), An atlas of radical cartography (pp. 13-26). LA: The Journal of Aesthetics and Protest Press.

Sloterdijk, P. (1998). Sphären: Blasen: Vol. 1. Frankfurt am Main: Suhrkamp.

----, (1999). Sphären: Globen: Vol. 2. Frankfurt am Main: Suhrkamp.

----, (2004). Sphären: Schäume: Vol. 3. Frankfurt am Main: Suhrkamp.

Sloterdijk, P. (2005). Foreword to a theory of spheres. In M. Ohanian \& J. C. Royoux (Eds.), Cosmograms (pp. 233240). New York: Lukas and Sternberg.

Twemlow, A. (2006). Bark to bytes. In J. Abrams \& P. Hall (Eds.), Else/Where: Mapping new cartographies of networks and territories (pp. 254-256). Minneapolis: University of Minnesota Design Institute.

von Uexküll, J. (1926). Theoretical biology (D. L. Mackinnon, Trans.). London: Kegan Paul.

Weizman, E. (2005). On extraterritoriality. Introductory address at Archipelago of exception: Sovereignties of extraterritoriality conference, Centre for Contemporary Culture, Barcelona.

i Halkevi, Kurdish and Turkish community centre has been a place of political and cultural solidarity between Kurds and left-wing Turks since it was established in 1984. It is an important centre in the organisation of the Kurdish diaspora across Europe. Some Turkish nationalists view the centre with suspicion due to its open support of the Kurdish struggle for self-determination.

ii The use of walking as a means of understanding the city has a long tradition from the Situationist dérive to more purposeful walks. For example, the feminist group Precarias a la deriva, use walking as a way of seeing the city through another perspective, of creating solidarity with others. They walked with women in Madrid who like them were employed in a range of 'precarious' employment in order to explore issues related to economy, labour and working conditions (Precarias a la deriva, 
2004). In geography this technique has also been used as 'talking whilst walking', a way of exploring the inter-relations between people, place and time (Anderson, 2004)

iii Careri (2003) gives a detailed history of walking and discusses it as a specifically aesthetic practice.

iv Processing is an open source programming language and environment initiated by Ben Fry and Casey Reas whilst at MIT Media Lab (Processing, n.d.)

$v$ Future iterations of the software will incorporate the scripts that generate the maps themselves, allowing users to directly create and store their own maps.

vi Feminist critiques of architecture have explored ways of 'multiplying' the restricted Euclidean space of normative architectural practice (Petrescu, 2006; Rendell, 2000).

vii The specific type of ANN used is a 'Self-Organising Map' [SOM], based on the algorithms developed by Teuvo Kohonen (Kohonen, 2001). ANN's have been used in an architectural context previously, typically in mapping 'real world' spatial information. For example, Centre for Evolutionary Computing and Architecture [CECA], based at University of East London have carried out a number of projects, notably (Derix, 2004). Typically, such algorithms are used for pattern recognition in images or language.

ix Jeremijenko's project, mentioned earlier, is very close to this model of thinking where plants and animals are taken seriously as actors in our world-her trees are in fact mapping their own 'bio-territory' (Jeremijenko, n.d.).

x These are the three behavioural properties given to each 'boid' or flock member by Reynolds (Reynolds).

xi For an introduction to the concept of 'spatial agency' as it sits within architectural and urban practice, see (Awan, 2011). 